\title{
金屬破斷面の電子顯微鏡による研究 $(\mathrm{II})$ *鐵合金の破斷面
}

\author{
若島久男** 上村 信***高橋 求****
}

Hisao Wakashima, Shin Uemura, Motomu Takahashi : On the Study of Microstracture of Fracture of Metals by Electron Microscopy (II). On the Fractured Surfaces of Steel. The fractured surfaces of steel were studied electron-microscopically, using the replica technique described in the previous report. (part 1)

The fractured surfaces of ductile materials such as pure iron and low carbon steel consist of small domains whose dimensions are $1 \sim 10 \mu$ in diameter. The boundary of this domain may correspond to the microcrack which is at first induced in the material in the process of fracture. On the contrary, the fractured surfaces of mild steel after fatigue test contain many streaks of crack originating from grain boundaries. Brittle materials such as high carbon steel or quenched Ni-Cr steel have very flat fractured surfaces, and the domains in these surfaces are larger than those of ductile materials. The mechanisms of fracture in brittle materials are unknown unless the relation batween the fractured surfaces and the structure are completely investigated.

(Received May 31, 1954)

\section{I. 緒 曾}

本報では第 1 報に述べたレプリカ法により，炭素鋼，特 殊鋼つ破断面を電子䋫溦鏡により 覞察した結果を報告す る.この方面つ研究性 Al-piess-replica 法儿よる

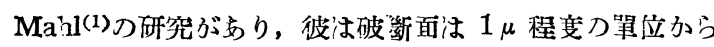

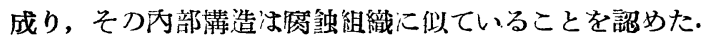
その後 J. Nutting 呿よび V. E. Cosslett(2)は珪素罁, 軟

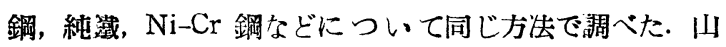
本(3)等はや注り A1-press replica 法により金屬表面つ研
小野(4)性それぞれ $\mathrm{Al}$ 扣よび炭素鋼つ疲勞破斷面を普通の メチル・メタクリル Al 法で調へている.

\section{II. 霓驗方法その他}

レプリカ作製については第 1 報に報告した通りである.

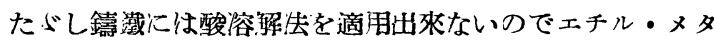
クリル樹指による高盜プレスにより破面つ型をとつた。し かしこつ方法は非常に不榷實で信解绞が低いつで本報告で は述べない。

この實驗に使用した材料は Table 1 に示す通りで, 純

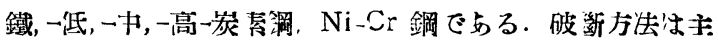
Table 1

\begin{tabular}{|c|c|c|c|c|c|}
\hline Materials & $\begin{array}{l}\text { Tensile } \\
\text { stxength } \\
\mathrm{kg} / \mathrm{mm}^{2}\end{array}$ & $\underset{\%}{\text { Elongation }}$ & $\begin{array}{c}\text { Hardness } \\
H_{R} B\end{array}$ & Treatment & Remark \\
\hline Pure i ron & - & - & 34.0 & Heated in $\mathrm{H}_{2}$ at $1300^{\circ}$ & - \\
\hline Low-carbon steel & 41.14 & 27.6 & 74.9 & Anneal & $0.1 \% \mathrm{C}$ \\
\hline Medium-carbon steel & 55.38 & 16. 0 & 90.0 & $" 1$ & $0.4 \% \mathrm{C}$ \\
\hline High-carb on steel & - & - & 98.2 & $" \prime$ & $1.1 \% \mathrm{C}$ \\
\hline Cast steel & 51.5 & 31.2 & 81.2 & " & $0.23 \% \mathrm{C} 0.28 \% \mathrm{Si}$ \\
\hline $\mathrm{Ni}-\mathrm{Cr}$ steel & 89.7 & 18.2 & $H_{B} 269$ & $\begin{array}{l}\text { Oil-quenched at } 850^{\circ} \text {, } \\
\text { tempered at } 600^{\circ}\end{array}$ & $\begin{array}{l}\text { SNC80 Charpy test values } \\
14 \mathrm{~kg}-\mathrm{m} / \mathrm{mm}^{2} \text { after raoi } \\
7 \mathrm{~kg}-\mathrm{m} / \mathrm{mm}^{2} \text { after cooling. }\end{array}$ \\
\hline
\end{tabular}

究を行つたが, 破斷面についてはふれていない.な和谷,

** 金濢大學工學部 $* * *$ 富士電機株式會社

**** 洼浦機栈整作所

* 1953 年邧季應用物理學會及び 1954 年 4 月本會東 京大會に發表.

(1) H. Mahl, Metalforschung, 2 (1947), 186.

(2) J. Nutting \& V. E. Cosslet, Nature, (1950), 165.

(3) 山本, 藤田, 本誌, A 15 (1951), 416
として引㖘破壇によつたが㣫揧扣よび疲勞, 破壇などにつ いても少しく實驗した。

\section{III. 䡒 驗 結 果}

\section{1.純鐵および低崖素鋼}

純鐵扣よび低炭素鋼つ弓張破断面は何れも同じ樣相を呈 し、たが純鐵は軟いために仰びが幾分多いように認められ る. 低炭素鋼の引張破斷面は通常見られる cup and cone

(4) 谷, 小野, J. Electron-Microscopy, Japan, 2(1954), No. 1 . 
狀を是し, Photo. 1 はその外綵部の shear 斷面の,

Photo. 2 は中尖部の平坦た tension 斷面の電㙷寫真で何

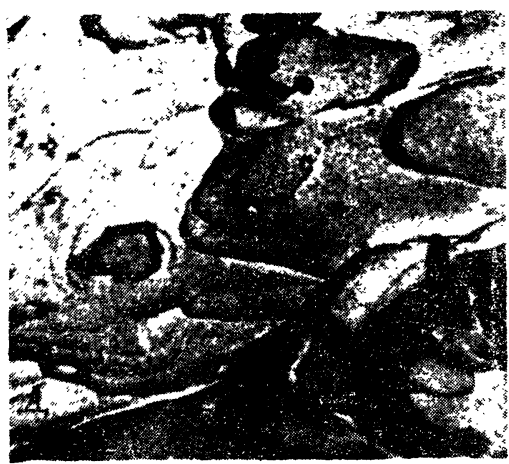

Photo. 1 Fracture by shear in tensile test of $0.1 \% \mathrm{C}$ steel.

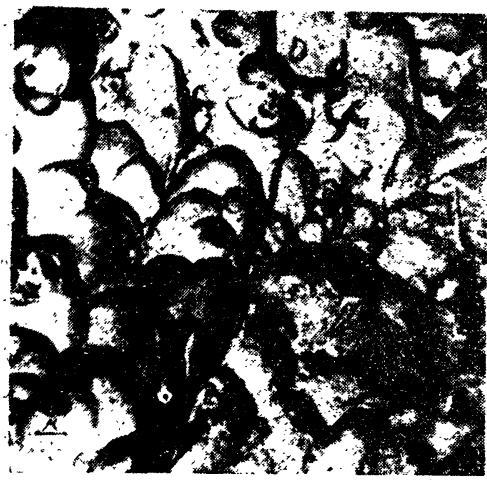

Photo. 2 Fracture by tensile strain in tensile test of $0.1 \% \mathrm{C}$ steel

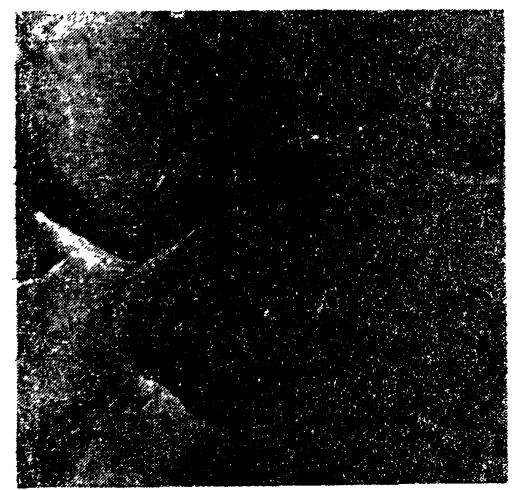

Photo. 3 Fracture in charpy's impact test. of $0.1 \% \mathrm{C}$ steel.

れもその破面 は $1 \sim 10 \mu$ 程 度の單位から なつている。 立體觀察によ れば各境界の 內部はそれぞ れ引浸方向に 篹过して挌り その先端は尖 つている. 從 つて破铢はま ず單位粒つ䚑 界に microcrack が禁生 しその內部の 軟い部分が塑 性變形を生 し，次第に細 くなり逐に分 離するものと 考えられる。 この粒界がそ の大きさから 考えて結晶粒 界と一致しな いことは結晶 粒つ大きさが 30〜50 $\mu$ の 程度であるこ とから推定出 來る. しかし 後述の中岑素 鋼に關与るる賔 驗から,この 最初にmicrocrack の墢生 ナる部分は格 子尔陷のあるところと考えられるから，結晶粒界も最初つ crack の發生には大いに闇係ちるものと思われる. shear 斷面と弓張斷面とではたが粘性變形つ力句が前者は張力方 向，後者は剪镂力力问といらだけ本質的の差異はない.な 呿粘性變形つ突端部心は小さい四部，凹部が認められる がここの部分は括そらく最後に分離した部分で微小な cup and cons 获点なすものである.

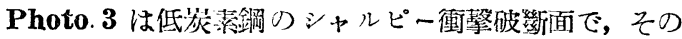

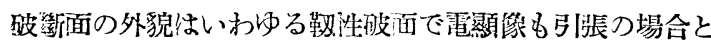

よく似た粘性變形が認められる，破面は引張試融つ shear 破斷面によく似ているが，變形つ先端性尖つていず值線状

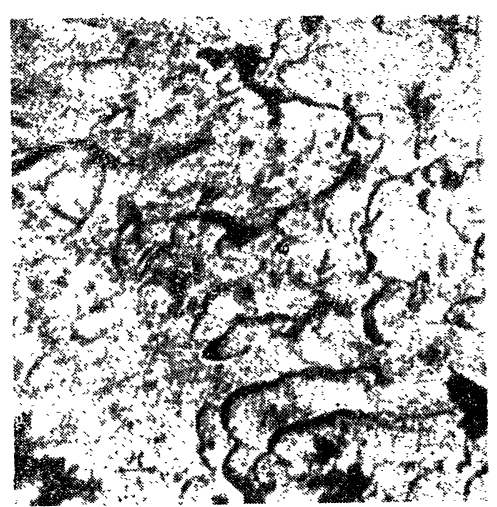

Photo. 4 Fracture in torsion test. of $0.1 \% \mathrm{C}$ steel.

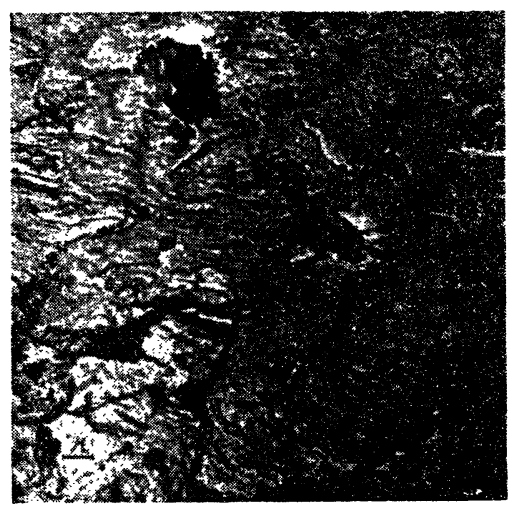

Photo. 5 Fracture in bending fatigue test of $0.1 \% \mathrm{C}$ steel.

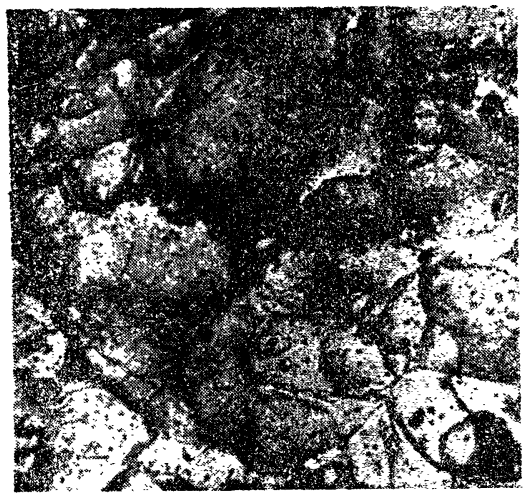

Photo. 6 Fracture in tensile test of normalized $0.4 \%$ carbon steel.
をなしてい る、尔なお台 衝揧破得新では 前方への十分 の件びが許さ れず, 側方へ 仲びるためと 考㝋られる。

Photo. 4 は低炭素鍓刀

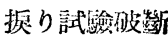
面の電顯窎滨 でその袁面 は非常に本滑 で品るが非常 に伸びた流動 變形の跡が認 められる，恑 り破斷に扮い。 ても引濃つ場 合と同じく， まず microcrack が酸等 しその肉部が 流動變形起起 ナものと考え られる。

Photo. 5 任低麦素銅の

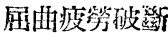
面で, 前远つ

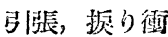
掔の場合とは 全く貲なる破 面の镁相量 し，臣ととど 粘栍戀形つ跡 が求められた い. 粒界之思 われる所加ら 破斷力゙進行し

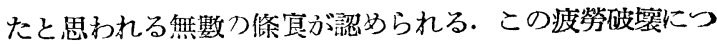
いては最近谷拾よび小野つ考察がある。

\section{2. 中岸 素銅}

Photo. 6 抢よび 7 生 $0.4 \%$ C 鍓つそれぞれ燒ならし

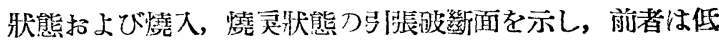
炭素鋼と间じく大きい㘘刓單位から出來ているが後者では 
大部分 $1 \mu$ 程度の小さい變形單位からなつている.これ待 燒入，燒受 $\left(500^{\circ}\right)$ 狀態で結晶粒內に微小な炭化物が分

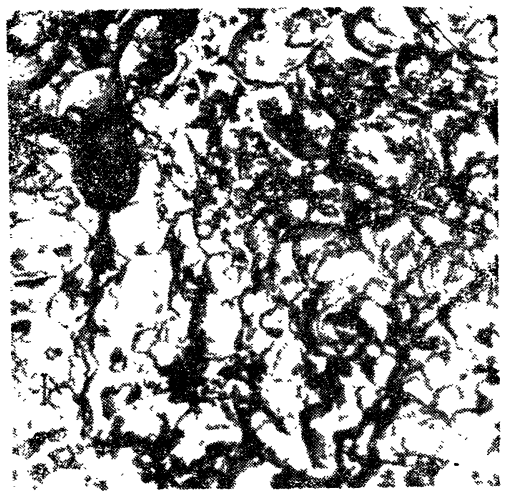

Photo. 7 Fracture in tensile test of quenched and tempered $0.4 \% \mathrm{C}$ steel.

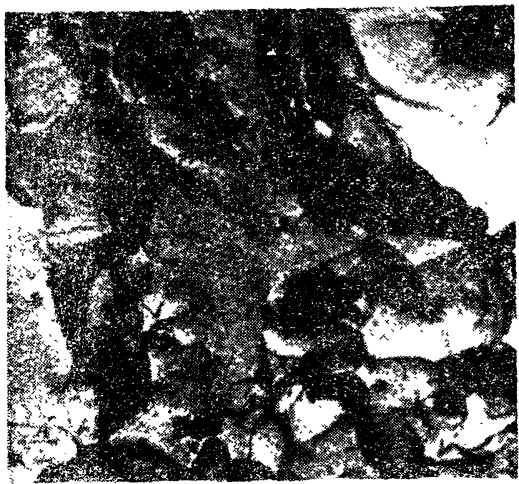

Photo. 8 Fracture in tensile test of $1.1 \% \mathrm{C}$ steel.

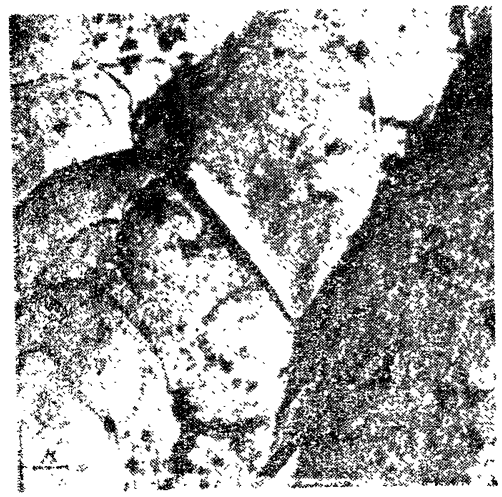

Phoho. 9 Fracture in tensile test of cast steel.

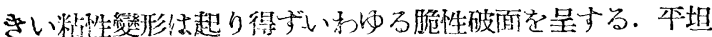

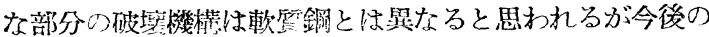
研究心李た放ばならぬ。

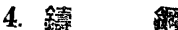

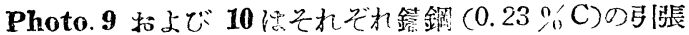

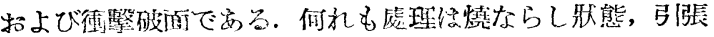

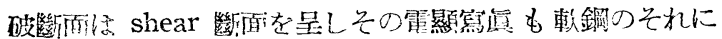

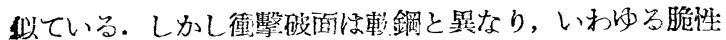

破面を呈し灰白色で伸びも少、，その電㙷像は軟鋼つ場合 によく似た伸びた大きい部分と微小な伸びが階段狀に集つ

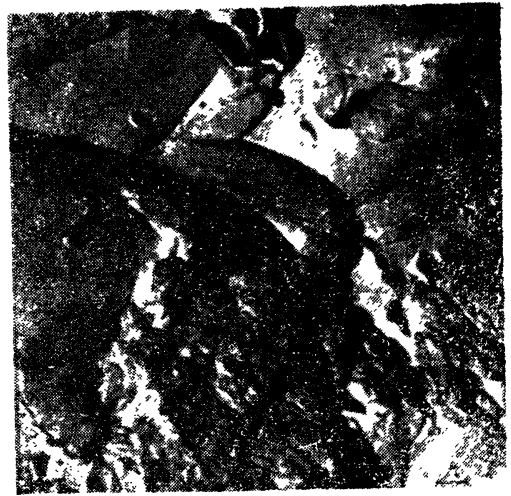

Photo. 10 Fracture in charapy's mipact test of cast steel.

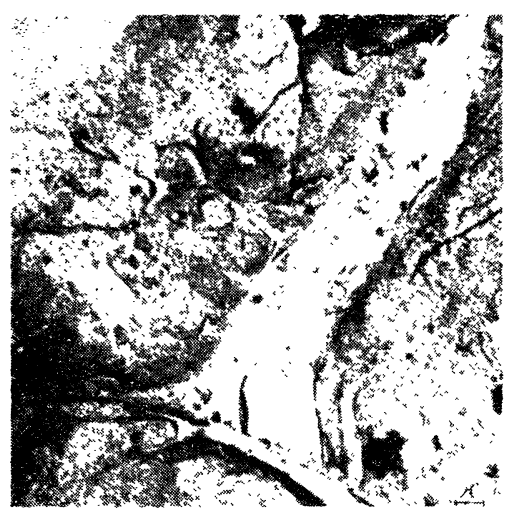

Photc. 11 Fracture in tensile test of quenched $\mathrm{Ni}-\mathrm{Cr}$ steel.

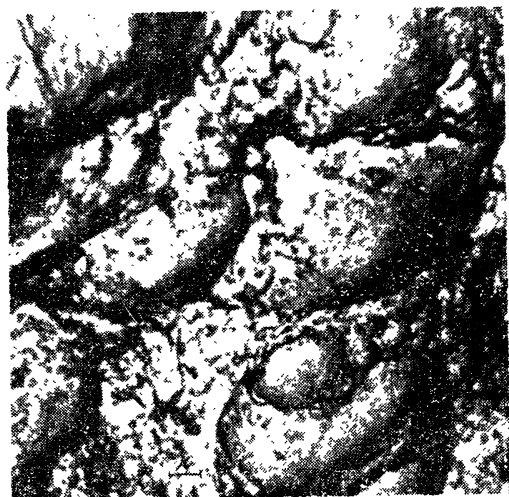

Photo. 12 Fracture in charpy's impact test of water-cooled after tempering
ている部分か

らなつてい

る.この階段

爿の部分は㣫

揧破壤の起默

となる部分が

多いため,一 $一$ つの起䂒から 磼生した流動 變形が長く續 かないで，次 くと新しい起 哭加らの破壞

が起るためこ の上らに階段 狀起呈与るも のと考える。

この階段狀の 部分が脆泩破 壊の特徽と考 之られるが今 後吩な检討 が必望で京 名.

\section{5. $\mathrm{Ni}-\mathrm{Cr}$ 鋼}

Photo. 11

倞䨀造用 $\mathrm{Ni}$ Cr 鋼の燒入 爿熊の引張破 斷面の霓顯像 でまる。燒入 れたものつ引 留破断面は Photo. 11 出 ら明らかなよ 万に本坦な留 い镇域少な つている. L 少し所以よ? ては軟屚に呿

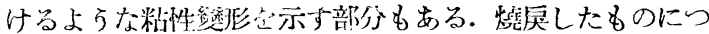

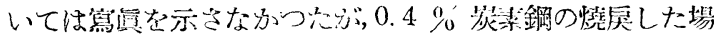
合の破斷面によく似た非常に小さい $1 \mu$ 程度の大きさの

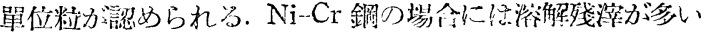

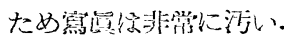

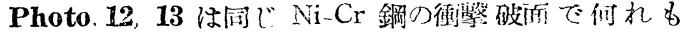

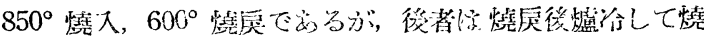


㞔脆泩を起さしてある，熱戻後急冷した材料は Photo. 12 儿示寸如く靶性材料公共通な流動變形が認められるが，脆

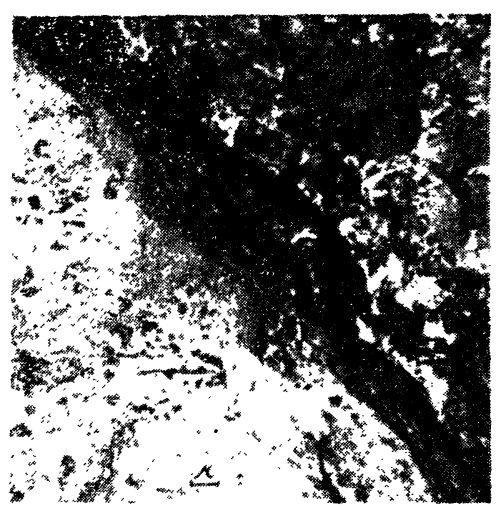

Photo. 13 Fracture in charpy's impact test of $\mathrm{Ni}-\mathrm{Cr}$ steel slow-cooletd after tempering.
性材料は

Photo. 13 少 らうかるよう に伸びの少い 平坦な破面が 見受叮られ 万.

\section{IV. 結 論}

以上鋼つ破 斷酒つ電子㙷 微鏡渗加ら得 られた結果を 姴約すると次

のようになる。

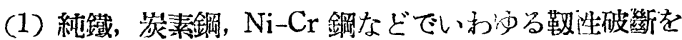
ナるもの小破斷面は 1 10 $\mu$ 程度の單位からなり，その
內部つ軟質部が流動變形をなす。

（2）燒入，燒戻した組織つ密なものは單位粒が小さいこ とから考えて，上つ單位粒刀境界法材料つ欠陷部で最初心 microcrack が弡生したところと考えられる。

（3）鑄鋼つ如く引背では䩓性破損圭生ずるが，衝揧では 脆泩破損をするものでは衝揧破面心階段状つ戀形つ跡が認 められるのが㗆泩材料つそれと買なつている。そつ原因に ついては明らかでない。

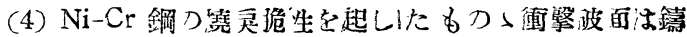
鋼つそれと基なり，變形つ少、本坦な部分が衿められ，脆 性つ原夾が壽嗵などの場合と異るように思われるが，今後

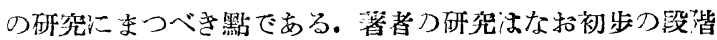
に学るが，今後さらに replica 法つ改这による破面つ微

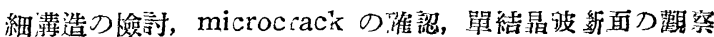

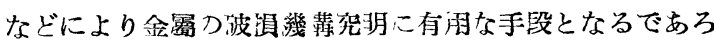
万.

最後に本寒驗實施に當り種ふの便宜を與えられ，また貴 重な材料をいただいた本學細牛期呚授，柴原助敉授に深謝 し，また熱心に實驗汇當られた西田君の勞を多とします。 